\title{
TRABALHO DOCENTE VOLUNTÁRIO NA EDUCAÇÃO SUPERIOR: PRECARIZAÇÃO DAS CONDIÇÕES DE TRABALHO NA ARGENTINA, BRASIL E CHILE ${ }^{1}$
}

\author{
TRABAJO DOCENTE VOLUNTARIO EN LA ENSEÑANZA SUPERIOR: \\ PRECARIZACIÓN DE LAS CONDICIONES DE TRABAJO EN ARGENTINA, BRASIL \\ Y CHILE
}

VOLUNTARY TEACHER WORK AT HIGHER EDUCATION: PRECARIOUSNESS OF WORK CONDITIONS IN ARGENTINA, BRAZIL AND CHILE

\author{
Savana Diniz Gomes MELO ${ }^{2}$ \\ Suzana dos Santos GOMES ${ }^{3}$
}

RESUMO: O trabalho docente tem passado por profundas transformações resultantes de sucessivas e imbricadas reformas educativas promovidas na educação superior nas últimas décadas, que buscam atender requerimentos do capitalismo. Nesse processo tem-se verificado o surgimento e/ou crescimento do trabalho docente voluntário. Tal fato tem impulsionado estudos sobre essa temática. Esse artigo oferece uma contribuição nesse sentido, expondo a experiência desse tipo de trabalho em três países: Argentina, Brasil e Chile. Partindo de revisão de literatura, o estudo de caráter exploratório que originou este artigo contou com entrevistas com professores desses países. O pressuposto orientador do estudo toma o trabalho docente voluntário como um contributo, dentre tantos, para a precarização e a intensificação do trabalho docente nas universidades. As entrevistas apontaram elementos que ratificam tal pressuposto e evidenciam a necessidade de ampliação e aprofundamento teórico de investigações sobre a temática e sua articulação às transformações do trabalho em geral, no capitalismo contemporâneo.

PALAVRAS-CHAVE: Trabalho docente voluntário. Precarização. Educação superior. Argentina, Brasil e Chile.

RESUMEN: El trabajo docente tiene pasado por profundas transformaciones resultantes de sucesivas y imbricadas reformas educacionales promovidas en la enseñanza superior en las últimas décadas, que buscan atender requisitos del capitalismo. En eso proceso pódense verificar el surgimiento y/o crecimiento del trabajo docente voluntario. Tal facto tiene conducido estudios acerca de esa temática. Ese artículo ofrece una contribución en ese

\footnotetext{
${ }^{1}$ Artigo contou com apoio financeiro da FAPEMIG.

${ }^{2}$ Universidade Federal de Minas Gerais (UFMG), Belo Horizonte - MG - Brasil. Professora Associada vinculada ao Programa de Pós-Graduação em Educação. Integra o Grupo de Pesquisa-ação sobre a Universidade (Universitátis/FaE/UFMG). Pós Doutora pela Universidade de La Coruña (UDC) e Universidade Federal de Minas Gerais (UFMG). ORCID: https://orcid.org/0000-0003-0415-5344. E-mail: sdgmufmg@ gmail.com 3 Universidade Federal de Minas Gerais (UFMG), Belo Horizonte - MG - Brasil. Professora Associada e Pesquisadora do Programa de Pós-Graduação em Educação. Integra o Grupo de Pesquisa-ação sobre a Universidade (Universitátis/FaE/UFMG). Pós Doutora pela Universidade de Lisboa (UL) e Universidade de São Paulo (USP). ORCID: http://orcid.org/0000-0002-8660-1741. E-mail: suzanasgomes@ fae.ufmg.br
} 
sentido, exponiendo a la experiencia de eso tipo de trabajo en tres países: Argentina, Brasil y Chile. Partiendo de una revisión de la literatura, el estudio de carácter exploratorio que ha originado ese artículo contó con entrevistas con profesores de esos países. El presupuesto orientador de ese artículo toma el trabajo docente voluntario como una contribución, entre tantas, para la precarización y la intensificación del trabajo docente en las universidades. Las entrevistas apuntaran elementos que ratificaron tal presupuesto y evidenciaran a la necesidad de ampliación y profundización teórica de investigaciones acerca de la temática y de su articulación con las transformaciones del trabajo en general, en el capitalismo contemporáneo.

PALABRAS-CLAVE: Trabajo docente voluntario. Precarización. Enseñanza superior. Argentina, Brasil y Chile.

ABSTRACT: Teacher work has passed through deep transformations resulting from successive and engendered education reforms promoted in Higher Education in the last decades, which seek to meet the demands of capitalism. In that process has been observed the appearing or increasing of voluntary teacher work. This fact has driven studies about that theme. The present paper offers a contribution towards that means, exposing the experience with that type of work in three countries: Argentina, Brazil and Chile. Beginning with a literature review, the exploratory study this paper resulted from consisted of interviews with teachers from those countries. The guiding presupposition of the study takes voluntary teacher work as a contribution, among many, for the precariousness and the intensification of teacher work at the universities. The interviews point out elements that ratify such presupposition and evince the need for theoretical amplification and deepening about the theme and its articulation to the transformation of work in general, in contemporary capitalism.

KEYWORDS: Voluntary teacher work. Precariousness. Higher education. Argentina, Brazil and Chile.

\section{Introdução}

Em meio a um processo de reestruturação capitalista que se expande nas últimas décadas como tentativa de dar resposta à uma profunda crise econômica e política global (BERNARDO, 1991), tem-se promovido em vários países sucessivas e imbricadas reformas na Educação Superior, para ajustá-la aos novos requerimentos do capital (SILVA JUNIOR, 2017).

Tais reformas universitárias, orientadas por organismos internacionais e assumidas como compromisso pelos chefes de Estado de diversos países, vem sendo estudadas por vários autores (SILVA; ANDRADE, 2016; FERREIRA, 2015), que revelam o contexto em que se inserem, o projeto em implementação, seu significado, algumas das suas consequências e desafios, entre outros.

RPGE- Revista on line de Política e Gestão Educacional, Araraquara, v. 24, n. esp. 1, p. 909-937, ago. 2020. e-ISSN:1519-9029. DOI: https://doi.org/10.22633/rpge.v24iesp1.13787 
No Brasil, os cortes de financiamento da educação superior, a privatização, a mercantilização, o produtivismo, a precarização e a intensificação do trabalho docente, a desestruturação da carreira e do regime de dedicação exclusiva, a perda de direitos trabalhistas e previdenciários, a terceirização, o adoecimento dos professores, as lutas pela universidade pública e gratuita são alguns dos temas já tratados na literatura da área (RHODEN; BOLZAN, 2019; CABRALES SALAZAR, 2018; FERRO; SILVA, 2017; MOREIRA; SILVA, 2017; KRAWULSKIL et al., 2017; KRAWULSKIL; RIBEIRO, 2013; GUIMARÃES; SOARES; CASAGRANDE, 2012; SGUISSARDI; SILVA JÚNIOR, 2009).

Assim, no Brasil, os sucessivos ataques à educação superior desde a década de 1990 se avolumaram e intensificaram a partir de 2004 e, sobretudo, a partir de 2016, com a ascensão de Temer seguido por Bolsonaro ao governo federal. A Emenda Constitucional no 95/2016, que limitou por vinte anos os gastos públicos em educação e saúde, entre outros estrangulamentos nos orçamentos das instituições federais de educação superior (IFES), cumpre papel fundamental nesse processo, na medida que estrangula os orçamentos já defasados das IFES e força a saída pela privatização.

Nesse quadro complexo tem-se observado o surgimento e/ou crescimento da figura do professor voluntário nas universidades públicas brasileiras.

O trabalho docente voluntário nessas instituições está sendo difundido de modo expressivo sob o argumento de que há demandas para continuidade dos professores nas IFES, em apoio às atividades de ensino e pesquisa, entre outras. Contudo, esse tipo de trabalho parece estar contribuindo muito para a ampliação da precarização do trabalho docente na área da educação.

A aprovação da Resolução nº 02, de 11 de setembro de 2018, do Conselho Nacional de Educação (CNE) e do Ministério da Educação (MEC), dá mais força a esse processo, pois afeta ainda mais o trabalho intelectual dos professores, especialmente nas universidades públicas federais. Tal Resolução instituiu diretrizes para a modalidade do trabalho voluntário na educação básica e superior, que já vem sendo utilizado nas universidades públicas com fundamento na Lei no 9.608/1998, aprovada pelo governo de Fernando Henrique Cardoso. De acordo com o Art. $1^{\circ}$ dessa Lei considera-se serviço voluntário a atividade não remunerada prestada por pessoa física a entidade pública de qualquer natureza ou a instituição privada de fins não lucrativos que tenha objetivos cívicos, culturais, educacionais, científicos, recreativos ou de assistência à pessoa.

O serviço voluntário não gera vínculo empregatício, nem obrigação de natureza trabalhista previdenciária ou afins. A figura do professor voluntário em universidades 
públicas se respalda também em resoluções específicas de cada IFES e está, mais uma vez, chancelada pelo MEC na Resolução nº 02/2018.

A revisão de literatura realizada revelou motivações que mobilizam o professor voluntário a (re)investir na carreira docente, após a aposentadoria. De modo geral, essa opção é fruto de um entrelaçamento de projetos e de experiências vivenciadas no percurso da carreira e trajetória profissional, que estão encadeadas entre si, configurando-se em uma trama de sentidos, presente em todo o ciclo profissional, que se atualiza, ampliando novos modos, tempos e condições (RHODEN; BOLZAN, 2019; KRAWULSKIL et al., 2017; KRAWULSKIL; RIBEIRO，2013; GUIMARAES; SOARES; CASAGRANDE，2012; RIVIERA, 2012; RIBEIRO; SMEHA, 2009; BOSI, 2007).

Nesse sentido, pretendeu-se neste artigo, discutir as características dessa modalidade de trabalho em três países da América Latina: Argentina, Brasil e Chile. Partiu-se do pressuposto de que o trabalho voluntário consiste em um dos elementos característicos da precariedade das condições de trabalho e emprego dos docentes nas universidades públicas e, ao mesmo tempo, conduz ao seu aprofundamento, com vistas ao alcance de objetivos precisos dos governos e empresários.

Quanto à metodologia, optou-se pela pesquisa exploratória de abordagem qualitativa organizada em duas etapas. A primeira consistiu na revisão de literatura a fim de verificar como a temática foi abordada nos três países, e seus resultados possibilitaram o conhecimento de aspectos da realidade do trabalho docente voluntário na Argentina, Brasil e Chile. A segunda etapa visou à realização de entrevista semiestruturada com três professores, sendo um de cada país. As entrevistas foram realizadas a partir de um roteiro comum, contendo dados de identificação e doze questões.

Pretendeu-se evidenciar nesse artigo como o trabalho docente voluntário na educação superior nos países pesquisados se realiza nos moldes atuais, como se constitui, sob que argumentos, e como os entrevistados percebem esse tipo de trabalho.

A expectativa é de que o presente artigo contribua de algum modo ao debate sobre o tema e abra novas problematizações sobre esse tipo de trabalho, sobre as políticas públicas em educação como um todo, sobre as transformações em curso na sociedade, e formas de enfrentamentos aos desafios postos à classe trabalhadora nesse quadro regressivo de direitos sociais, trabalhistas e previdenciários que assola o planeta. 


\section{Trabalho Docente Voluntário na percepção dos professores entrevistados}

Neste tópico apresenta-se os excertos mais significativos das respostas dadas às questões do estudo. Objetivou-se com as entrevistas captar o contexto em que o trabalho voluntário em geral e docente surgiu em cada país; como foi normatizado nacionalmente e nas universidades públicas; como se realiza na prática docente; e como tem sido percebido pelos docentes entrevistados. Para tanto, foram convidados professores universitários de três países, de perfil intelectual crítico à sociedade e às políticas públicas em educação, situados em diferentes etapas da trajetória docente, sendo dois professores ativos, com experiência há mais de 10 anos de exercício docente; e um professor aposentado, com 27 anos de trabalho na universidade.

A experiência argentina foi retratada por Adriana Graciela Migliavacca, Professora Adjunta da Universidad Nacional de Lujan, en regimen de trabajo Ordinaria con dedicación exclusiva, y que posé 10 años y 5 meses de trabalho en la universidade ${ }^{4}$. Mestre em Política e Gestão da Educação (UNLu), graduada em Ciências da Educação.

Para a experiência chilena, o entrevistado foi Felipe Andres Zurita Garrido, Profesor e Investigador de la Escuela de Pedagogía en Historia y Ciencias Sociales, de la Universidad Academia de Humanismo Cristiano, profesor efectivo, que posé 12 años de trabalho em la universidade 5 . Doutor em Educação (UFMG), graduado em História e Ciências Sociais. No Brasil, a entrevista foi realizada com Antonio Julio de Menezes Neto, Professor Titular da Universidade Federal de Minas Gerais, pós-doutor em Educação (UFRJ) e em Desenvolvimento, Agricultura e Sociedade (UFRRJ), graduado em Ciências Sociais, em regime de trabalho de dedicação exclusiva, aposentado há oito meses que, atualmente, exerce o trabalho voluntário $\left(\mathrm{P} 1^{6}\right)$.

Indagados sobre o significado do trabalho voluntário em geral (P2), os entrevistados apresentaram respostas que apontam alguns aspectos comuns e outros singulares. Em comum chama a atenção o fato de se constituir um trabalho não remunerado, que pode ser realizado tanto em locais de trabalho propriamente ditos, como em atividades políticas, religiosas, filantrópicos, culturais, etc. Para Felipe, o trabalho voluntário no Chile é entendido

4 "Em regime de trabalho comum com dedicação exclusiva, com 10 anos e 5 meses de trabalho na universidade." 5 "Professor e Pesquisador da Escola de Pedagogia em História e Ciências Sociais, da Universidade Academia de Humanismo Cristão, professor efetivo, com 12 anos de trabalho na universidade."

6 “As respostas dos entrevistados às perguntas do roteiro de entrevista foram aportadas ao longo do texto pelo conteúdo, seguido da letra $\mathrm{P}$ e do seu respectivo número." 
en relación a dos condiciones: 1) como el trabajo realizado por una persona que no recibe un salario a cambio de la realización del mismo y 2) como aquel trabajo realizado por la propia voluntad, motivado por algún interés distinto a la obtención de un salario que podría ser de diversa naturaleza: estatus; religioso; político; cultural; solidario; entre otros. De esta forma, entiendo al trabajo voluntario como un fenómeno que rompe con la situación más genérica de relación entre alguien que compra y alguien que vende trabajo. En un nivel distinto, el trabajo voluntario en algunos casos también sea una vía más o menos obligatoria para acceder a una situación de trabajo asalariado, de manera directa o indirecta ${ }^{7}$.

Antonio Julio, por sua vez, destacou a temática no Brasil e afirma que

Em nossa sociedade capitalista, trabalho voluntário poderia existir em atividades de cidadania, militância, trabalhos totalmente filantrópicos ou temporários em situações de calamidade. Por exemplo, trabalhos em partidos políticos ou sindicatos, com cargos de direção por tempo limitado ou trabalho em ações sociais vinculados, por exemplo, a atividades de igrejas para com as populações vulneráveis.

Antônio Julio chama a atenção, entretanto, para o fato de que nesse último caso, “[...] o trabalho público, do estado, deve ser a principal atividade e os trabalhadores devem ser remunerados. Por isto, o trabalho voluntário não substitui o trabalho remunerado. No capitalismo, o trabalhador vende sua força de trabalho, que já é explorada, a outro".

Adriana abordou a questão na Argentina, para ela, no mesmo sentido dos entrevistados anteriores, admite que "[...] en determinadas circunstancias, puede llegar a realizarse en el marco de alguna actividad de militancia política o social que se traza algún compromiso con las necesidades de los sectores más postergados de la sociedad"8.

Contudo, chama a atenção para o fato de se constituir como um elemento de precarização do trabalho e do acesso a ele. Em suas palavras:

[...] en muchos casos, es una figura que promueve o motoriza la precarización de las condiciones de trabajo. En muchas ocasiones, y en determinadas actividades, puede constituirse en un mecanismo perverso para el acceso a algún campo laboral, o para sumar algún antecedente valorado en el currículum vitae personal. En este sentido, es importante tener presente que es una forma de trabajo que puede profundizar las desiguales condiciones de acceso a ciertos campos profesionales. La idea

7 “Em relação a duas condições: 1) como o trabalho realizado por uma pessoa que não recebe um salário em troca da realização do mesmo e 2) como aquele tipo de trabalho realizado por vontade própria, motivado por algum interesse para além da obtenção de um salário, que poderia ser de natureza diversa: status; religioso; político; cultural; solidário; entre outros. Deste modo, entendo o trabalho voluntário como um fenômeno que rompe com a situação mais genérica de relação entre alguém que compra e alguém que vende trabalho. Em um nível distinto, o trabalho voluntário, em alguns casos, pode ser também um caminho mais ou menos obrigatório para ter acesso a uma situação de trabalho assalariado, de modo direto ou indireto."

8 “[...] em determinadas circunstâncias, pode ser realizada no âmbito de alguma atividade de militância política ou social que traça um compromisso com as necessidades dos setores mais negligenciados da sociedade."

RPGE- Revista on line de Política e Gestão Educacional, Araraquara, v. 24, n. esp. 1, p. 909-937, ago. 2020. e-ISSN:1519-9029. DOI: https://doi.org/10.22633/rpge.v24iesp1.13787 
voluntario esconde que, mиy probablemente, nadie elija trabajar sin percibir remuneración alguna'.

\section{Quanto à existência e funcionamento do trabalho docente voluntário no país (P3)}

as respostas dos entrevistados evidenciam que, embora sob distintas nominações, esse tipo de trabalho é presente nas universidades, inclusive as públicas estatais. Enquanto os entrevistados da Argentina e do Brasil responderam positivamente, localizando o seu surgimento em regulamentação nacional na década de 1990 e 2000, o chileno afirmou que este não é trabalho regular no seu país, embora se apresente em normativas de instituições de educação superior desde o início da década de 1980, na figura do profesor $^{10}$ ad-honorem.

Antônio Júlio afirma simples e categoricamente que no Brasil o trabalho docente voluntário "Infelizmente, existe nas universidades públicas”. Felipe responde que a legislação nacional não regulamenta o trabalho voluntário na educação básica e ele não é comum.

El trabajo docente voluntario no es una figura regular en Chile. En el caso de las y los Profesores de Educación Básica y Educación Media del Sector Público tienen su actividad regulada por la Ley $N^{o} 19.070$ Estatuto de Profesionales de la Educación (promulgada el 27.06.1990) y por la Ley $N^{o}$ 20.903 de Desarrollo Profesional Docente (promulgada el 04.03.2016). En estos cuerpos legales no se considera el trabajo voluntario. En el caso de las y los Profesores de Educación Básica y Educación Media del Sector Privado tienen su actividad regulada por el Decreto con Fuerza de Ley $N^{o} 1$ Código del Trabajo (promulgado el 31.07.2002) y por la Ley $N^{o} 20.903$ de Desarrollo Profesional Docente (promulgada el 04.03.2016). En estos cuerpos legales no se considera el trabajo voluntario ${ }^{11}$.

Contudo, afirma Felipe, o trabalho voluntário regulamentado para a educação superior na figura do profesor ad-honorem é comum nas Instituições de Educação Superior Públicas e Privadas.

En el caso de los Profesores que trabajan en la Educación Superior en el Sector Público tienen la condición de Empleados Públicos y su actividad

9 “[...] em muitos casos, é uma figura que promove ou motiva a precarização das condições trabalhistas. Em muitas situações e em determinadas atividades, pode se constituir em um mecanismo perverso para o acesso a algum campo laboral, ou para somar alguma formação valorizada no currículo vitae pessoal. Neste sentido, é importante ter em mente que esta é uma forma de trabalho que pode aprofundar as condições desiguais de acesso a certos campos profissionais. A ideia de voluntário esconde que, muito provavelmente, ninguém escolha trabalhar sem receber nenhuma remuneração."

${ }^{10}$ Professor.

11 "O trabalho voluntário docente não é uma questão regulamentada no Chile. No caso das e dos Professores do Ensino Fundamental e Ensino Médio do Setor Público, têm sua atividade regulamentada pela Lei № 19.070 Estatuto de Profissionais da Educação (promulgada em 27.06.1990) e pela Lei $\mathrm{N}^{\circ} 20.903$ de Desenvolvimento Profissional Docente (promulgada em 04.03.2016). O trabalho voluntário não é considerado nesses órgãos legais. No caso das e dos Professores do Ensino Fundamental e Ensino Médio do Setor Privado, têm sua atividade regulamentada pelo Decreto com Força de Lei $\mathrm{N}^{\circ} 1$ Código do Trabalho (promulgado em 31.07.2002) e pela Lei $\mathrm{N}^{\circ} 20.903$ de Desenvolvimento Profissional Docente (promulgada em 04.03.2016). Nestes órgãos legais não se considera o trabalho voluntário." 
está regulada por el Decreto con Fuerza de Ley $N^{\circ} 29$ que sistematiza al Estatuto Administrativo (promulgado el 16.06.2004) y por regulaciones internas que cada Universidad Estatal construye para sí misma. En el Decreto con Fuerza de Ley $N^{o} 29$ no se considera la figura del trabajo voluntario. No obstante, en las reglamentaciones que se han originado en el contexto de cada Universidad Estatal fue posible identificar un espacio para el trabajo voluntario. Este es el caso del Reglamento Universitario $N^{o} 553$ denominado Reglamento del Personal Académico Ad Honorem de la Universidad de Chile promulgado el 25 de Enero de 1982 en plena Dictadura Cívico Militar. Dicho Reglamento sigue siendo utilizado, por ejemplo, en la Facultad Derecho Universidad de Chile, donde de forma reciente se continúa haciendo convocatorias a Concursos Académicos que consideran la figura del trabajo voluntario o ad-honorem. En un Concurso Académico de inicios del año 2020 de dicha Unidad Académica se convocaba a 14 Cargos Académicos Regulares y 10 Cargos Académicos adhonorem, estableciendo que tienen 6 horas de trabajo semanal asociado y se encuentran mayoritariamente orientadas al apoyo de las actividades de Docencia. Esta figura de trabajo se asemeja a la del Trabajo de Ayudantes de Cátedra. En el caso de los Profesores que trabajan en la Educación Superior en el Sector Privado tienen su actividad regulada por el Decreto con Fuerza de Ley $N^{o} 1$ Código del Trabajo (promulgado el 31.07.2002). En este cuerpo legal no se considera el trabajo voluntario. Más allá de lo señalado anteriormente, un espacio de trabajo ad-honorem común para las Instituciones de Educación Superior Publicas y Privadas es el Trabajo de Ayudante de Cátedra. Este trabajo consiste en una actividad de apoyo al/la Docente responsable de la Cátedra y a las y los Estudiantes participantes de la misma ${ }^{12}$.

Felipe esclarece o que é o Ayudante de Cátedra ${ }^{13}$, suas atividades, quem pode ocupar esse posto, como ele é reconhecido nas universidades e pelo que aspiram:

[...] colabora en diferentes tipos de actividades al interior de un Curso o Disciplina: en las actividades de Docencia, en la elaboración de evaluaciones, en la realización de asesorías a las y los Estudiantes, entre

12 "No caso dos Professores que atuam no Ensino Superior do Setor Público, possuem o status de Funcionários Públicos e sua atividade é regulamentada pelo Decreto com Força de Lei $n^{\circ} 29$, que sistematiza o Estatuto Administrativo (promulgado em 16/06/2004) e pelos regulamentos internos que cada Universidade Estadual estabelece para si. No Decreto com Força de Lei $n^{\circ} 29$ não se considera a questão do trabalho voluntário. No entanto, nos regulamentos que se originaram no contexto de cada Universidade Estadual, foi possível identificar um espaço para o trabalho voluntário. É o caso do Regulamento Universitário $\mathrm{n}^{\circ} 553$, chamado Regulamento do Pessoal Acadêmico Ad Honorem da Universidade do Chile, promulgado em 25 de janeiro de 1982 em plena Ditadura Cívico Militar. Tal Regulamento segue sendo utilizado, por exemplo, na Faculdade de Direito da Universidade do Chile, onde recentemente continua realizando chamadas a Concursos Acadêmicos que consideram a figura do trabalho voluntário ou ad-honorem. Em um Concurso Acadêmico do início do ano 2020 da referida Unidade Acadêmica, foram convocados 14 Cargos Acadêmicos Regulares e 10 Cargos Acadêmicos ad-honorem, estabelecendo que possuíam 6 horas de trabalho semanal e que seriam, principalmente, orientados ao apoio às atividades de Ensino. Esta figura de trabalho se assemelha à do Trabalho de Professor Assistente. No caso dos Professores que trabalham no Ensino Superior no Setor Privado têm sua atividade regulamentada pelo Decreto com Força de Lei $N^{\circ} 1$ Código do Trabalho (promulgado em 31.07.2002). Neste organismo legal não se considera o trabalho voluntário. Para além do que foi dito anteriormente, um espaço de trabalho ad-honorem comum para as Instituições de Ensino Superior Públicas e Privadas é o Trabalho de Professor Assistente. Este trabalho consiste em uma atividade de apoio ao/à Docente responsável pela Cátedra e às e aos Estudantes participantes da mesma."

${ }^{13}$ Professor Assistente.

RPGE- Revista on line de Política e Gestão Educacional, Araraquara, v. 24, n. esp. 1, p. 909-937, ago. 2020. e-ISSN:1519-9029. DOI: https://doi.org/10.22633/rpge.v24iesp1.13787 
otras. El Ayudante de Cátedra puede ser un Estudiante Regular de la Universidad que realiza esta función de forma paralela a sus Estudios de Pregrado o Posgrado, como así también, puede ser un Profesional ya titulado que ejerce funciones laborales tanto dentro como fuera de la Universidad. A propósito de la realización de las actividades de Ayudante de Cátedra, el o la Ayudante puede o no recibir un salario por sus actividades, lo que varía de Universidad en Universidad. De todas formas, la realización de la actividad de Ayudante de Cátedra es algo que es reconocido como una actividad formativa importante en el contexto de la Carrera Académica Universitaria, de hecho, se considera muchas veces como un canal de ingreso a la misma que continua con posterioridad en la realización de Estudios de Posgrado ${ }^{14}$.

Adotando outra linha de raciocínio, Felipe problematiza a existência desse tipo de trabalho na educação superior chilena, aportando dados desse nível de ensino e da precarização do trabalho docente nas instituições, que mantém vínculos trabalhistas precários, temporários, sem proteção jurídica e sem antiguidade; férias; licenças médicas; entre outros direitos. Segundo Felipe,

[...] quizás la figura del trabajo voluntario o trabajo ad honorem en el Trabajo Docente en la Educación Superior no es del todo necesaria, puesto que existe un tipo de organización del mismo en que un número masivo de Profesoras y Profesoras tienen un vínculo precario con las Instituciones. El caso de las Universidades es muy llamativo, puesto que actualmente existen 59 Universidades: 18 Estatales y 41 Privadas que emplean en conjunto a cerca de 73.109 Profesoras y Profesores. De este toral cerca de 14.492 Docentes trabajan en 2 o más Universidades. Del mismo total cerca de 29.920 tienen menos de 11 horas de trabajo contratadas a la semana y cerca de 18.776 tienen entre 11 y 23 horas de trabajo contratadas a la semana. Estos datos reflejan la figura del vínculo laboral a Honorarios, que corresponde a un vínculo por el cual el o la Docente desarrolla un Curso o Disciplina en un Semestre y la Universidad le paga exclusivamente las horas de trabajo asociadas a la realización de ese Curso o Disciplina. Esta tipología de vínculo laboral está ampliamente extendida en el Sistema Universitario e implica que ese perfil de Profesoras y Profesoras desarrollen vínculos laborales precarios, acotados en el tiempo, sin protección jurídica (no se considera antigüedad; no considera el pago de vacaciones; no considera licencias médicas; etc.) y es evidentemente conveniente para las Universidades desde el punto de vista económico, puesto que, además de los ahorros ya mencionados, las y los Docentes que trabajan a Honorarios realizan otras actividades que no están consideradas

14 “'...] colabora em diferentes tipos de atividades em um Curso ou Disciplina: nas atividades de Docência, na elaboração de avaliações, na realização de acessórias às e aos Estudantes, entre outras. O Professor Assistente pode ser um Estudante Regular da Universidade que realiza esta função em forma paralela a seus Estudos de Graduação ou Pós-Graduação, bem como pode ser um Profissional já graduado que exerce funções laborais tanto dentro da Universidade, como fora dela. Em relação à realização das atividades de Professor Assistente, o que muda em relação a cada Universidade é que o/a Assistente pode ou não receber um salário por suas atividades. De qualquer forma, a realização da atividade de Professor Assistente é algo que se reconhece como uma atividade formativa importante no contexto da Carreira Acadêmica Universitária, de fato, é frequentemente considerado como uma porta de entrada para a mesma, que continua mais tarde na conclusão dos estudos de Pósgraduação." 
en el pago realizado, a saber: participación en reuniones; participación en comisiones académicas de diversa naturaleza y con destaque en los procesos de evaluación de la calidad de Universidades y Programas Académicos de Pregrado y Posgrado asociado a la Acreditación; preparación de las actividades de Docencia; retroalimentación a Estudiantes fuera del horario de clase; entre otras ${ }^{15}$.

Felipe chama a atenção para os efeitos deste tipo de vínculo precário e cita a publicação de Cantillana y Portilla (2019) como referência para dimensioná-los. Entretanto, ressalta a naturalização dessa situação. Em suas palavras: "La situación de este perfil de Docentes es compleja y extendida, por lo tanto, su existencia es asumida como normal en el escenario de las Universidades chilenas"16. Felipe destaca, ainda, que os docentes, frente a inexistência de sindicatos da categoria, buscam se organizar coletivamente para defender suas reivindicações: "Frente a la ausencia de un Sindicato Nacional de Docentes Universitarios, en algunas Universidades grandes este perfil de Docentes han avanzado hacia la organización de Sindicatos de Profesores a Honorarios con el objetivo de llevar adelante pautas propias al interior de sus Instituciones"17.

Como ocorre no Chile e no Brasil, Adriana informa que o trabalho docente voluntário existe na educação formal argentina no nível universitário. Afirma que este ocorre sob distintas formas, e também é desenvolvido por meio de projetos e fundações:

No tengo información sobre su existencia actual en otros niveles educativos del sistema formal. Existe, bajo múltiples formas, en distintos proyectos llevados adelante por organizaciones sociales o fundaciones. Entiendo que el marco regulatorio es la ley de trabajo voluntario, ya que dentro de esta

15 “[...] talvez a imagem do trabalho voluntário ou ad honorem no Trabalho Docente no Ensino Superior não seja plenamente necessária, tendo em vista que há um tipo de organização do mesmo na qual um grande número de Professores e Professoras tem um vínculo precário com as Instituições. No caso das Universidades é muito chamativo, visto que atualmente existem 59 Universidades: 18 Federais e 41 Privadas que empregam, conjuntamente, 73.109 Professores e Professoras. Deste total, 14.492 Docentes trabalham em 2 ou mais Universidades. Do mesmo modo, um total de 29.920 têm menos de 11 horas de trabalho contratadas na semana. Estes dados refletem a figura do vínculo trabalhista a Honorários, que corresponde a um vínculo pelo qual o/a Docente realiza em um curso ou Disciplina em um semestre e a Universidade lhe paga exclusivamente pelas horas de trabalho realizadas neste Curso ou Disciplina. Este tipo de vínculo trabalhista é amplamente difundido no Sistema Universitário e implica que esse perfil de professores desenvolva relações trabalhistas precárias, limitadas no tempo, sem proteção legal (não é considerada antiguidade; não se considera pagamento de férias; não se considera licença médica; etc.) e é evidentemente conveniente para as Universidades do ponto de vista econômico, dado que, além das economias já mencionadas, as e os Docentes que trabalham por hora realizam outras atividades que não são consideradas no pagamento realizado, a saber: participação em reuniões; participação em comissões acadêmicas de diversas natureza e com destaque nos processos de avaliação de qualidade das Universidades e Programas Acadêmicos de Graduação e Pós-graduação associados à Acreditação; preparação das atividades de Docência; retroalimentação à Estudantes fora do horário de aula, entre outras."

16 "A situação deste perfil de Docente é complexa e extensa, portanto, sua existência é assumida como normal no cenário das Universidades chilenas."

17 "Diante da ausência de um Sindicato Nacional de Docentes Universitários, em algumas Universidades grandes este perfil de Docentes tem avançado até à organização de Sindicatos de Professores a Honorários com o objetivo de levar adiante pautas próprias ao interior de suas Instituições."

RPGE- Revista on line de Política e Gestão Educacional, Araraquara, v. 24, n. esp. 1, p. 909-937, ago. 2020. e-ISSN:1519-9029. DOI: https://doi.org/10.22633/rpge.v24iesp1.13787 
normativa se contempla a las actividades educativas. No dispongo información cuantitativa en el caso del trabajo docente voluntario en un nivel general ${ }^{18}$.

Adriana elucida a existência nas universidades estatais argentinas de uma normativa nacional denominada "convenio colectivo de trabajo para docentes universitários"19, que estabelece as categorias docentes, mas chama a atenção para o fato de que nem todas as universidades aderiram a ele, e são orientadas por seus próprios estatutos. Esse é o caso da principal universidade do país, a Universidade de Buenos Aires (UBA).

En el nivel universitario, el convenio colectivo de trabajo para docentes universitarios, homologado en 2015, contempla las siguientes categorías de docentes: Regulares u ordinários; Interinos; Suplentes; Extraordinarios. Esta categoría se contempla para los casos en que, con carácter excepcional, se designen profesores que, por sus reconocidas trayectorias, hayan sido nombrados como Consultos, Eméritos, Honorarios, Visitantes e Invitados. Esta categoría no se ajusta a la del "docente voluntario" o "adhonorem", más allá de que estos docentes puedan ser convocados para alguna tarea puntual que no implique el cobro de alguna retribución. Es importante aclarar que no todas las universidades han adherido al convenio colectivo de trabajo. Éste es el caso, por ejemplo, de la Universidad de Buenos Aires (UBA). El estatuto de esta universidad contempla la figura de los ad-honorem y los define como aquellos que 'con carácter ad-honorem" colaboran en la enseñanza: los docentes autorizados y los docentes libres $[\ldots]^{20}$.

Aponta dados sobre o quantitativo trabalho docente voluntário no país e na UBA, as áreas que mais acolhem esse tipo de trabalho e as reivindicações sindicais sobre o tema.

En ese nivel educativo, en 2018, se calculaba que había 14000 docentes trabajando ad-honorem (en forma voluntaria). De esos 14000, 9600 (el $68 \%)$ eran de la (UBA). En el caso de la UBA, su Facultad de Medicina es la que concentra la mayoría de los ad honorem. Según un artículo del diario Página 12: 'El dato surge de un relevamiento realizado por las propias

18 "Não tenho informações sobre sua existência atual em outros níveis educacionais do sistema formal. Existe, sob muitas formas, em diversos projetos levados adiante por organizações sociais ou fundações. Entendo que o âmbito regulatório é a lei de trabalho voluntário, já que dentro desta normativa se contempla as atividades educacionais. Não disponho de informação quantitativa no caso do trabalho docente voluntário em um nível geral."

${ }^{19}$ Convênio coletivo de trabalho para docentes universitários.

${ }^{20}$ No nível universitário, o convênio coletivo de trabalho para docentes universitários, homologado em 2015 , contempla as seguintes categorias de docentes: Regulares ou ordinários; Interinos; Suplentes; Extraordinários. Esta categoria se contempla para os casos em que, com caráter excepcional, se designem professores que, por suas reconhecidas trajetórias, tenham sido nomeados como Consultores, Eméritos, Honorários, Visitantes e Convidados. Esta categoria não se ajusta à de "docente voluntário" ou "ad-honorem", além de que estes docentes possam ser convocados para alguma tarefa pontual que não implique a cobrança de alguma retribuição. É importante esclarecer que nem todas as universidades aderiram ao convênio coletivo de trabalho. Este é o caso, por exemplo, da Universidade de Buenos Aires (UBA). O estatuto desta universidade contempla a figura dos adhonorem e os define como aqueles que "com caráter ad-honorem colaboram com o ensino: os docentes autorizados e os docentes livres [...]." 
universidades después de que, en la última paritaria del sector, el Gobierno se comprometiera a avanzar en 2019 en la regularización de estos profesores - un reiterado reclamo de los gremios docentes -. Para comenzar a hacerlo, resolvió aportar una partida de 50 millones de pesos. Ahora la Secretaría de Políticas Universitarias (SPU), los dirigentes sindicales y los rectores de universidades negocian para definir los criterios de distribución de esos fondos. Los gremios advirtieron que los 50 millones son insuficientes, ya que cubrirían poco más de 400 cargos: menos de un 3 por ciento de los afectados. ("Catorce mil docentes trabajan sin cobrar", Diario Página 12, 9 de noviembre de 2018) ${ }^{21}$.

Em sua reposta, Adriana evidencia como o trabalho ad-honorem se expressava no país, em 2013. "Según el último anuario estadístico publicado por la SPU, en 2013, el total de docentes que trabajaban en las universidades nacionales y en los institutos universitarios era 121.208. De esos 121.208, 2.095 trabajaban ad-honorem"22.

Indagada sobre a posição do sindicato docente acerca desse problema, Adriana evidencia o protagonismo de uma organização mais combativa, as medidas de força adotadas sobretudo uma greve em 2005 e as respostas do governo, supostamente para resolver o tema do trabalho voluntário.

El problema de los docentes ad-honorem ha sido tomado por los sindicatos, en especial por aquellos adheridos a la CONADU Histórica. De acuerdo con la información obtenida, el tema tomó un importante protagonismo, en la agenda sindical, en el marco de una extendida huelga que se desarrolló en 2005. En el caso de la UBA, donde toma mayor representatividad, fue la Asociación Gremial Docente (AGD) (adherida a CONADU Histórica) la que le imprimió dinamismo al reclamo. Allí se constituyó una comisión específica del gremio que lleva adelante los reclamos por salario, aseguradora de riesgo de trabajo (ART), obra social, capacitación, licencias, becas, proyectos de investigación. Desde entonces, el reclamo es incluido en todos los pliegos reivindicativos que se plantean en los conflictos gremiales y en las mesas de negociación paritaria. En la última paritaria de 2019, el Gobierno se comprometió a avanzar en la regularización de los profesores ad-honorem y aportó una partida de 100 millones de pesos, a repartir entre las distintas universidades. Sin embargo, los gremios planteaban que estos fondos eran insuficientes para solucionar la situación. En el caso de la UBA, los fondos no llegaban a alcanzar para rentar al 10

21 "Neste nível educacional, em 2018, se calculava que havia 14000 docentes trabalhando ad-honorem (de forma voluntária). Destes 14000, 9600 (68\%) eram da (UBA). No caso da UBA, sua Faculdade de Medicina é a que concentra a maioria dos ad honorem. Segundo um artigo do Diário Página 12: 'Os dados surgem de uma pesquisa realizada pelas próprias universidades depois que, na última assembleia do setor, o Governo se comprometeu avançar, em 2019, na regularização desses professores - uma reivindicação reiterada dos sindicatos educacionais -. Para começar, decidiu contribuir começando com 50 milhões de pesos. Agora a Secretaria de Políticas Universitárias (SPU), os dirigentes sindicais e os reitores de universidades negociam para definir os critérios de distribuição destes fundos. Os sindicatos advertiram que os 50 milhões são insuficientes, já que cobriram pouco mais de 400 cargos: menos de 3 por cento dos afetados. ("Catorze mil docentes trabalham sem receber", Diário Página 12, 9 de novembro de 2018)."

22 "Segundo o último anuário estatístico publicado pela SPU, em 2013, o total de docentes que trabalham nas universidades nacionais e nos institutos universitários era 121.208. Destes 121.208, 2.095 trabalham adhonorem."

RPGE- Revista on line de Política e Gestão Educacional, Araraquara, v. 24, n. esp. 1, p. 909-937, ago. 2020. e-ISSN:1519-9029. DOI: https://doi.org/10.22633/rpge.v24iesp1.13787 
por ciento de los ad honorem. Asimismo, este programa de financiamiento de renta sólo contempla a docentes ad honorem "puros", es decir, a aquellos que solamente sean ayudantes de primera con dedicación parcial y no tengan ningún otro cargo rentado en la universidad (docente o no docente). (La negociación para rentar al 10 por ciento de los docentes ad honorem de la UBA, Diario Página 12, 20 de septiembre de 2019). En el caso de la UBA, el fondo aportado por el Ministerio de Educación Nacional permitía efectivizar 875 cargos de docentes que venían trabajando sin percibir salario. Desde la AGD, se planteaba la necesidad de que esta regularización se llevara adelante según el criterio de antigüedad. En este marco, deslizaban sus críticas 'contra las gestiones que imponen su discrecionalidad como patronal' y expresaban 'defendemos asimismo el derecho de las comisiones ad honorem a elevar ante las autoridades los empadronamientos públicos realizados y ordenados priorizando el criterio de mayor antigüedad, a partir del valioso trabajo de les compañeres que se empadronan, se organizan y batallan para derrotar el trabajo gratuito en nuestra universidad'. (Información extraída de la página web de AGD) $)^{23}$.

Finalizando sua resposta, Adriana apresenta mais dados sobre o trabalho voluntário (ad-honorem), trazendo aportes de artigos de agrupações políticas de esquerda, e de forma conclusiva, revela o significado desse tipo de trabalho, que pode ser definido como uma superexploração dos trabalhadores docentes:

Algunos datos interesantes para dimensionar la situación: en un artículo de "La Izquierda Diario", Matías Alcántara, docente ad honorem afirma que, en la Facultad de Medicina: '[...] más del $60 \%$ de los docentes son ad honorem y muchos estudiantes. Es una situación crítica. Pensemos que los futuros profesionales están siendo formados por estudiantes. Es un sistema terrible de explotación porque no perciben salarios por muchísimos años'. Asimismo, se planteaba que en la Facultad de Ciencias Económicas, el $56 \%$ del plantel docente es ad honorem. En la Facultad de Ciencias Sociales, a

23 “O problema dos professores ad honorem foi abordado pelos sindicatos, especialmente por aqueles que ingressam na CONADU Histórica. Segundo as informações obtidas, a questão teve um papel importante na agenda sindical, no contexto de uma greve prolongada ocorrida em 2005. No caso da UBA, onde se tem uma maior representatividade, foi a Associação Sindical Docente (AGD) (aderida pela CONADU História) que imprimiu dinamismo à reivindicação. Neste âmbito, foi criada uma comissão específica do sindicato que levou adiante as reinvindicações por salário, asseguradora de riscos de trabalho (ART), assistência social, capacitação, licenças, bolsas, projetos de pesquisa. Desde então, a reivindicação foi incluída em todas as reivindicações levantadas em conflitos sindicais e em mesas de negociação conjuntas. Na última assembleia de 2019, o Governo se comprometeu a avançar na regularização dos professores ad-honorem e contribuiu com 100 milhões de pesos, a dividir entre as universidades. No entanto, os sindicatos reivindicavam que estes fundos eram insuficientes para solucionar a situação. No caso da UBA, os fundos não eram suficientes para pagar 10 por cento dos ad honorem. Do mesmo modo, este programa de financiamento de renda só contempla aos docentes ad honorem "puros", ou seja, aqueles que apenas sejam ajudantes de primeira com dedicação parcial e não tenham nenhum outro cargo remunerado na universidade (docente ou não docente). (A negociação para pagar 10 por cento dos docentes ad honorem da UBA, Diário Página 12, 20 de setembro de 2019). No caso da UBA, o fundo fornecido pelo Ministério da Educação Nacional permitirá efetivar 875 cargos de docentes que vinham trabalhando sem receber salário. A partir do AGD, houve necessidade de que essa regularização fosse realizada de acordo com o critério de antiguidade. Neste âmbito, discorriam suas críticas 'contra as gestões que impõem sua discrição como empregadores' e expressavam 'também defendemos o direito das comissões ad honorem a elevar frente às autoridades dos padrões públicos realizados e ordenados, priorizando o critério de maior antiguidade, a partir do valioso trabalho dos companheiros empregados, se organizam e batalham para derrotar o trabalho gratuito em nossa universidade'. (Informação extraída da página da web da AGD).” 
partir de relevamientos realizados por los docentes, se calculaba que 800 trabajaban ad-honorem. Los docentes que trabajan ad-honorem se ven privados, de hecho, de un conjunto de derechos adquiridos por quienes perciben un salario. Se enfrentan a la situación de tener que costear, por su propia cuenta, los viáticos, la formación y los materiales de estudio. No gozan de obra social, de aportes jubilatorios ni de seguro de riesgo de trabajo. Desde la gremial AGD se ha propuesto la confección de un padrón con los docentes en esta situación. Se ha constituido una comisión específica del gremio que lleva adelante los reclamos por salario, Aseguradora de Riesgo de Trabajo (ART), obra social, capacitación, licencias, becas, proyectos de investigación. Es decir, el conjunto de los derechos que gozan los trabajadores de la docencia y la investigación universitarias ${ }^{24}$.

\title{
Sobre a existência de trabalho docente voluntário na universidade em que
}

trabalha (P4), Felipe informa que na universidade privada em que atua a figura o trabalho ad-

honorem é recente e convive com o trabalho remunerado simbólico ou de baixa remuneração.

\begin{abstract}
La Universidad Academia de Humanismo Cristiano es una Universidad Privada de orientación político-académica progresista, fue creada en el año 1975 por parte del Cardenal Raúl Silva Henríquez con el objetivo de cobijar a Academias y Académicos que estaban siendo expulsados de las Universidades Tradicionales (Públicas y Privadas) por su orientación política, todo esto en el contexto de la Dictadura Cívico Militar. Actualmente existe en dicha Universidad la figura de Ayudante de Cátedra que tradicionalmente era remunerada con un valor pequeño. Desde fines del año 2019 esto cambió, ahora el trabajo de Ayudante de Cátedra es ad honorem, debido a que actualmente la Universidad atraviesa una situación financiera delicada y las personas que dirigen la misma optaron por reducir costos en dicha área. El trabajo de Ayudante de Cátedra está regulado por un Reglamento que sólo regula lo referido a su selección a través de Concursos. Las exigencias para ser Ayudante de Cátedra son de carácter académico, o sea, tener calificaciones ubicadas en la parte alta en los respectivos Cursos. Los derechos de los Ayudantes de Cátedra son difusos, no están establecidos con claridad, sólo se habla de las condiciones que deben poseer y las tareas que deben abordar. La cantidad de Ayudantes de Cátedra es variable en cada uno de los Semestres, debido a que se trabaja en razón de un Ayudante de Cátedra por cada Curso o Asignatura. El lugar privilegiado de su acción es durante el desarrollo de las actividades del Curso o Disciplina, puesto que se espera que estén presentes y colaborando
\end{abstract}

24 “Alguns dados interessantes para mensurar a situação: em um artigo de 'La Izquierda Diario", Matías Alcántara, docente ad honorem afirma que, na Faculdade de Medicina: '[...] mais de $60 \%$ dos docentes são ad honorem e muitos estudantes. É uma situação crítica. Imagina-se que os futuros profissionais estejam sendo formados por estudantes. É um sistema terrível de exploração porque não recebem salário há muitos anos'. Também se colocava que na Faculdade de Ciências Econômicas, 56\% do quadro docente é ad honorem. Na Faculdade de Ciências Sociais, a partir de revelações realizadas pelos docentes, calculava-se que 800 trabalhavam ad-honorem. Os docentes que trabalham ad-honorem se veem privados, de fato, de um conjunto de direitos adquiridos por quem recebe um salário. Enfrentam a situação de ter que pagar, por conta própria, as diárias, a formação e os materiais de estudo. Eles não possuem assistência social, contribuições para a aposentadoria ou seguro contra riscos trabalhistas. O sindicato AGD propôs a criação de um cadastro dos professores nessa situação. Se constituiu uma comissão específica do sindicato que leva adiante as reivindicações salariais, Asseguradora de Risco de Trabalho (ART), assistência social, capacitação, licenças, bolsas, projetos de pesquisa. Ou seja, o conjunto de direitos de que gozam os trabalhadores da docência e pesquisa universitária."

RPGE- Revista on line de Política e Gestão Educacional, Araraquara, v. 24, n. esp. 1, p. 909-937, ago. 2020. e-ISSN:1519-9029. DOI: https://doi.org/10.22633/rpge.v24iesp1.13787 
en las actividades de Docencia. Fuera de este espacio, trabajan en reuniones de coordinación con las y los Profesores responsables de los Cursos o Disciplinas. Las condiciones de trabajo de los Ayudantes de Cátedra son precarias, no cuentan con espacios de trabajo ni de equipos para el adecuado desarrollo de sus actividades. En general su dedicación semanal es limitada, no superando las 5 horas de trabajo, considerando asistencia a las clases y preparación de materiales. Esto último, ciertamente depende muchas veces del perfil de relación que establecen con las Profesoras y Profesores responsables de los Cursos o Disciplinas, puesto que es conocido que sus actitudes son variables, yendo desde la indiferencia hasta el exceso de carga de trabajo en los puntos extremos. En el caso de la Universidad Academia de Humanismo Cristiano entiendo que no existe una organización de Ayudantes de Cátedra. Desde mi punto de vista, este tipo de trabajo es complejo de evaluar, puesto que en general es ad honorem o remunerado de manera simbólica. En el caso de la figura ad honorem no me parece adecuado y este semestre sería la primera vez que se experimentaría en la Institución. En el caso de ser remunerado, ese pago bajo o simbólico muchas veces era un ingreso valioso para estudiantes que con dificultades económicas importantes y que, a la vez, están interesados en desarrollar actividades que les permitan seguir una Carrera Académica. Por otra parte, es necesario pensar esto con las condiciones de estudio general que se desarrollan en Chile, marcado por un alto nivel de endeudamiento y acceso aún limitado a la política de Gratuidad Universitaria ${ }^{25}$.

Antônio Julio responde que o trabalho docente universitário existe na universidade em que atua, a Universidade Federal de Minas Gerais (UFMG), e declara que ele mesmo se

25 “A Universidade Academia de Humanismo Cristão é uma Universidade Privada de orientação políticoacadêmica progressista, foi criada no ano 1975 por parte do Cardeal Raúl Silva Henríquez com o objetivo de proteger as Academias e Acadêmicos que eram expulsos das Universidades Tradicionais (Públicas e Privadas) por sua orientação política, tudo isso no contexto da Ditadura Cívico Militar. Atualmente, há na mesma Universidade a figura do Professor Assistente que tradicionalmente era remunerada com um valor baixo. A partir do fim do ano 2019, isso mudou, agora o trabalho de Professor Assistente é ad honorem, devido a que atualmente a Universidade atravessa uma situação financeira delicada e as pessoas que realizam a mesma optaram por reduzir custos na referida área. O trabalho de Professor Assistente está regulamentado por um Regulamento que apenas regula o referido cargo e sua seleção através de concursos. As exigências para ser Professor Assistente são de caráter acadêmico, ou seja, ter qualificações situadas na parte alta nos respectivos Cursos. Os direitos dos Professores Assistentes são difusos, não estão estabelecidos com clareza, apenas se fala das condições que devem ter as tarefas que devem abordar. A quantidade de Professores Assistentes é variável em cada um dos Semestres, devido a que se trabalha em razão de um Professor Assistente por cada Curso ou Disciplina. O lugar privilegiado de sua ação é durante o desenvolvimento das atividades do Curso ou Disciplina, já que se espera que estejam presentes e colaborando nas atividades de Docência. Fora deste espaço, trabalham em reuniões de coordenação com as e os Professores responsável dos Cursos ou Disciplinas. As condições de trabalho dos Professores Assistentes são precárias, não contam com espaços de trabalho nem equipes para o desenvolvimento adequado de suas atividades. Em geral, sua dedicação semanal é limitada, não superando as 5 horas de trabalho, considerando assistência às aulas e elaboração de materiais. Este último, certamente depende muitas vezes do perfil de relação que estabelecem com as Professoras e Professores responsáveis pelos Cursos ou Disciplinas, uma vez que se sabe que suas atitudes são variáveis, indo desde a indiferença até o excesso de carga de trabalho nos pontos extremos. No caso da Universidade Academia de Humanismo Cristão entendo que não há uma organização de Professores Assistentes. Do meu ponto de vista, este tipo de trabalho é complexo de avaliar, posto que em geral é ad honorem ou remunerado de modo simbólico. No caso da figura ad honorem não me parece adequado e este semestre seria a primeira vez que se experimentaria na Instituição. No caso de ser remunerado, este baixo ou simbólico pagamento muitas vezes era uma remuneração valiosa para estudantes com grandes dificuldades econômicas e que, por sua vez, estão interessados em realizar atividades que lhes oportunizam seguir uma Carreira Acadêmica. Por outro lado, é necessário pensar nisso com as condições de um estudo geral que se desenvolvam no Chile, marcado por um alto nível de endividamento e acesso ainda limitado à política de Gratuidade Universitária." 
encontra nesta situação. Adriana, por sua vez, afirma que na universidade em que atua existe dois tipos de trabalho docente voluntário - o ad-honorem e o ajudante de segunda - e que as normativas sobre o tema são definidas de forma diferenciada pelas unidades acadêmicas ou departamentos da instituição.

El estatuto de la Universidad Nacional de Luján (UNLu) contempla que los docentes auxiliares y profesores puedan desempeñar sus funciones ad-honorem. La última versión del estatuto es del año 2000 pero es muy probable que la posibilidad del trabajo ad-honorem ya estuviera incluida desde el estatuto fundacional de la universidad. En términos generales, y de acuerdo con mis conocimientos, son nombrados como ad-honorem, los docentes que se encuentran en la siguiente situación: profesores extranjeros que participan de algún proyecto de la universidad. La condición para participar, por ejemplo, de un proyecto de investigación es que el profesor sea docente de la universidad. En ese marco, se hace el nombramiento ad-honorem; ayudantes estudiantiles (formalmente denominados "ayudantes de segunda"). La UNLu está organizada en cuatro unidades académicas o departamentos: Educación, Tecnología, Ciencias Básicas y Ciencias Sociales. Cada departamento dicta su normativa sobre esta situación. En el departamento de Educación no se puede nombrar a los ayudantes estudiantiles en forma ad-honorem. Estos estudiantes cobran una retribución. En el resto de los departamentos está habilitado el nombramiento ad-honorem. El Departamento de Ciencias Sociales tiene a todos los ayudantes estudiantiles nombrados adhonorem. Los departamentos de Ciencias Básicas y de Tecnología lo hacen en forma mixta. Todos estos ayudantes son nombrados por concurso público. Tienen una carga horaria equivalente a una dedicación simple, es decir, nueve horas semanales, de las cuales seis tienen que ser presenciales. Los años trabajados se computan como antigüedad y se les cubre la obra social ${ }^{26}$.

26 “O estatuto Universidade Nacional de Luján (UNLu) contempla que os docentes auxiliares e professores possam desempenhar suas funções ad-honorem. A última versão do estatuto é do ano 2000, mas é muito provável que a possibilidade do trabalho ad-honorem já estivesse incluída desde o estatuto estrutural da universidade. Em termos gerais, e de acordo com meus conhecimentos, são nomeados como ad-honorem, os docentes que se encontram na seguinte situação: professores estrangeiros que participam de algum projeto da universidade. A condição para participar, por exemplo, de um projeto de pesquisa é que o professor seja docente da universidade. Neste âmbito, se realiza a nomeação ad-honorem; assistentes estudantis (formalmente denominados "assistente secundários"). A UNLu está organizada em quatro unidades acadêmicas ou departamentos: Educação, Tecnologia, Ciências Básicas e Ciências Sociais. Cada departamento dita sua normativa sobre esta situação. No departamento de Educação não se pode nomear aos assistentes estudantis em forma ad-honorem. Estes estudantes ganham uma retribuição. Nos demais departamentos está habilitada a nomeação ad-honorem. O Departamento de Ciências Sociais tem a todos os assistentes estudantis nomeados adhonorem. Os departamentos de Ciências Básicas e de Tecnologia o fazem de forma mista. Todos estes assistentes são nomeados por um concurso público, têm uma carga horária equivalente a uma dedicação simples, ou seja, nove horas semanais, das quais seis precisam ser presenciais. Os anos trabalhados se calculam como antiguidade e lhes pagam assistência social."

RPGE- Revista on line de Política e Gestão Educacional, Araraquara, v. 24, n. esp. 1, p. 909-937, ago. 2020. e-ISSN:1519-9029. DOI: https://doi.org/10.22633/rpge.v24iesp1.13787 
Adriana chama a atenção para o fato dos docentes ad-honorem ainda existirem na UNLu, posto que ela aderiu ao convênio coletivo de trabalho que previu sua extinção em até um ano após sua homologação e não admite a figura de ajudante de segunda, o que demonstra que as legislações não vêm sendo cumpridas em sua universidade, o que também deve ocorrer em outras universidades do país. O trabalho precário e a exploração persistem, como regra.

Desde que la UNLu adhirió al convenio colectivo de trabajo, en 2015, no debería haber docentes nombrados ad-honorem (esta situación debía regularizarse un año después de la adhesión a este convenio). Sin embargo, el convenio colectivo no incluye a los estudiantes estudiantiles ${ }^{27}$.

Segundo Adriana, os docentes voluntários participam do sindicato da categoria, com os mesmos direitos que possuem os docentes remunerados. Sua contribuição sindical é opcional, contudo, somente quando ela ocorre podem ter acesso aos subsídios oferecidos pela organização.

En la gremial docente de la UNLu (ADUNLu) tienen plenos derechos, como cualquier docente remunerado. Pueden votar en las asambleas y participar en las elecciones de la comisión directiva. Se pueden afiliar al sindicato sin hacer ningún tipo de aporte. Tienen derecho a hacer huelga y a participar de todo tipo de reclamo sindical. También pueden optar por pagar una cuota sindical que les da acceso a todos los subsidios que otorga el sindicato (para participar en congresos, para fotocopias, etc). El valor de esa cuota es el equivalente al $2 \%$ del salario establecido para el ayudante de primera (actualmente alrededor de $\$ 200$ mensuales) ${ }^{28}$.

Questionados sobre as principais motivações dos governos para a criação desse tipo de trabalho (P5), os entrevistados destacaram a desresponsabilização do Estado em relação aos direitos da população, o estímulo à mercantilização da educação superior, a precarização do trabalho docente, e o aprofundamento de lógicas competitivas e meritocráticas entre os docentes. Felipe afirma que no Chile o trabalho docente voluntário de docentes universitários cumpre a função de via de acesso à carreira acadêmica, para atender a demanda de trabalhadores das universidades privadas que tiveram grande expansão a partir da

27 “Desde que a UNLu aderiu ao convênio coletivo de trabalho, em 2015, não deveria haver docentes nomeados ad-honorem (esta situação deveria ser regularizada um ano depois da adesão a este convênio). No entanto, o convênio coletivo não inclui aos estudantes."

28 "No sindicato docente da UNLu (ADUNLu) há plenos direitos, como qualquer docente remunerado. Podem votar nas assembleias e participar nas eleições na comissão diretiva. Se podem afiliar ao sindicato sem fazer nenhum tipo de contribuição. Têm direito à greve e a participar de todo tipo de reinvindicação sindical. Também podem optar por pagar uma cota sindical que lhes dá acesso a todos os subsídios que outorga o sindicato (para participar em congressos, para Xerox, etc). O valor desta cota é equivalente a $2 \%$ do salário estabelecido para assistentes primários (atualmente cerca de \$200 mensais)." 
década de 1980, com a venda de serviços (ensino), captação de matrículas (estudantes) e subsídios do Estado (créditos universitários). Em suas palavras:

El trabajo ad honorem de los Ayudantes de Cátedra es de largo aliento. Imagino que logró posicionarse como una vía de acceso a estatus que les permitiera a las y los estudiantes hacer un espacio para acceder a la Carrera Académica, a modo de peaje obligatorio a pagar. La figura de las Profesoras y Profesoras a Honorarios también es de larga data en el Sistema de Educación Superior en Chile y se masificó desde la década de 1980 en adelante cuando la Dictadura Cívico Militar creo las condiciones necesarias para la creación de nuevas Universidades Privadas que paulatinamente favorecieron una masificación del acceso a la Universidad a fines de la década de 1990 y principios de la década del 2000, gracias al apoyo estatal a la política de créditos universitarios de fácil acceso y costosos en el corto plazo. Dicha masificación de la matrícula universitaria facilitó la demanda de Profesoras y profesores a Honorarios para un Sistema Universitario que funciona en base al autofinanciamiento a través de la captación de matrículas y la venta de servicios ${ }^{29}$.

Antônio Julio considera que se trata de mais uma situação de trabalho precário na universidade e chama a atenção para a importância dos sindicatos docentes não menosprezarem o tema. Em suas palavras:

[...] li a norma, mas não sei desde quando e nem a justificativa coletiva, para dizer aqui. Penso que a maioria dos docentes voluntários está nesta situação por motivos de trabalho inconcluso. Ou seja, realizam parte dos mesmos trabalhos que realizavam na ativa. Porém, as condições de trabalho precarizam mais, pois perdem o vínculo com a Universidade. Esta é mais uma situação de trabalho precarizado e, por isto, deveria fazer parte das lutas sindicais. Não sei o quantitativo que se encontra no voluntariado, mas sei que o número é significativo. É uma questão que não pode ser menosprezada pelos sindicatos, já que diz respeito ao todo da categoria. Mas da forma como é hoje, o trabalhador voluntário fica privado das atividades sindicais, pois está lá, teoricamente, porque quer e não recebe nada.

Já Adriana afirma que o trabalho voluntário pode afiançar a desresponsabilização do Estado em relação aos direitos da população. Por outro lado, aprofunda lógicas competitivas e meritocráticas.

29 "O trabalho ad honorem dos Professores Assistentes é de fôlego. Eu imagino que ele tenha conseguido se
posicionar a partir de um caminho que lhe proporciona o acesso ao status que permitiria aos alunos abrir espaços
para acessar a Carreira Acadêmica, como um pedágio obrigatório a pagar. A figura das Professoras e Professores
Honorários também é de longa data no Sistema de Ensino Superior no Chile e se massificou desde a década de
1980 adiante, quando a Ditaduta Cívico Militar criou as condições necessárias para a criação de novas
Universidades Privadas que paulatinamente favoreceram um acesso em massa à Universidade no final da década
de 1990 e início da década de 2000, graças ao apoio estatal à política de créditos universitários de fácil acesso a
curto prazo. Tal massificação da matrícula universitária facilitou a demanda de Professoras e professores a
Honorários para um Sistema Universitário que funciona com base no autofinanciamento através da capacitação
de matrículas e venda de serviços." RPGE- Revista on line de Política e Gestão Educacional, Araraquara, v. 24, n. esp. 1, p. 909-937, ago. 2020. e-ISSN:1519-9029. DOI: https://doi.org/10.22633/rpge.v24iesp1.13787 
Creo que, cuando se trata de un trabajo voluntario que se desarrolla en el marco de organizaciones sociales, puede llegar a afianzar un esquema en el cual el Estado se desentiende de su responsabilidad de velar que se garanticen los derechos de la población. Asimismo, es un sistema de trabajo que profundiza las lógicas competitivas $y$ meritocráticas, ya que implica que quien está dispuesto a trabajar sin percibir remuneración alguna cuenta con medios materiales complementarios para sostenerse y para financiar los propios gastos que genera la actividad ${ }^{30}$.

\section{Considerou-se relevante saber por que o docente universitário recorre a esse tipo}

\section{de trabalho, identificando os benefícios e as perdas (P6). Para Felipe,}

los estudiantes y profesionales que acceden al trabajo de Ayudante de Cátedra en la modalidad ad honorem lo hacen por buscar estatus y las credenciales académicas suficientes para ingresar a la Carrera Académica o Profesional exitosa en el futuro. Ganan experiencia y valorización de sus antecedentes académicos. Pierden tiempo. Las y los Profesores que trabajan en la modalidad a Honorarios, si bien no corresponde a un trabajo voluntario o ad honorem, sí acceden a un trabajo precario. Hacen esto para tener acceso al empleo, en el contexto de un Sistema de Educación Superior en general y Universitario en particular, que se organiza en base a la competencia y el autofinanciamiento en base a la captación de matrículas y venta de servicios, lo que genera una inclinación por mantener esta modalidad de trabajo y mantener controlado el costo de la contratación de Docentes a Jornada Fija. Las y los Docentes a Honorarios ganan solamente el tener empleo y pierden una serie de garantías que conlleva el trabajo regular". Antonio Julio, na mesma linha de reflexão, afirmou que "o trabalho docente é cumulativo ao longo do tempo. Assim, quase sempre, o docente quando se aposenta, por exemplo, tem sempre trabalhos para terminar, seja relativos a projeto de pesquisa ou orientações de mestrandos e doutorandos ${ }^{3 l}$.

Ainda segundo Antonio Julio, "não se pode esquecer que o trabalho docente mais ameno é atrativo para professores aposentados, que podem contribuir com sua experiência.

\footnotetext{
30 “Acredito que, quando se trata de um trabalho voluntário que se realiza no âmbito de organizações sociais, pode acabar consolidando um esquema em que o Estado desconsidera sua responsabilidade de garantir os direitos da população. Do mesmo modo, é um sistema de trabalho que aprofunda as lógicas competitivas e meritocráticas, já que implica que quem está disposto a trabalhar sem remuneração alguma conta com meios materiais complementares para se sustentar e para financiar os próprios gastos que a atividade gera."

31 “os estudantes e profissionais que acessam ao trabalho de Professor Assistente na modalidade ad honorem o fazem para buscar status e credenciais acadêmicas necessárias para ingressar na Carreira Acadêmica ou Profissional exitosa no futuro. Ganham experiência e valorização em sua formação acadêmica. Perdem tempo. As e os Professores que trabalham na modalidade a Honorários, embora não corresponda a um trabalho voluntário ou ad honorem, entram em contato com um trabalho precário. Fazem isso para ter acesso ao emprego, no contexto do Ensino Superior em geral e Universitário em particular, que se organiza na base da competência e do autofinanciamento baseado na captação de matrículas e venda de serviços, o que gera uma inclinação a manter esta modalidade de trabalho e manter controlados os custos da contratação de Docentes de Jornada Fixa. As e os Docentes horistas ganham somente para ter emprego e perdem uma série de garantias que implica o trabalho regular."
} 
Por isso, um outro tipo de vínculo que não seja o voluntariado, poderia ser instituído". Já Adriana destacou que na Argentina,

ser docente universitario da prestigio y antecedentes que son positivamente valorados en el currículum vitae. El aceptar trabajar ad-honorem puede ser una oportunidad para ingresar al ámbito académico. Segundo Adriana "Quienes ganan son las autoridades, que ahorran presupuesto. Y el propio capital, que disputa por el destino que se le dan a los fondos públicos. Quienes pierden, son los trabajadores, tanto los que trabajan sin ser remunerados como los que reciben su remuneración, ya que repercute en la "flexibilización" de las condiciones de trabajo de todo el colectivo de docentes $^{32}$.

Dando prosseguimento, perguntados sobre as consequências desse tipo de trabalho na universidade (P7), Felipe argumentou que "as consecuencias del trabajo de Ayudantes de Cátedra ad honorem en la Universidad tienen como consecuencia el acceso a apoyo de estudiantes o profesionales a las actividades de Docencia sin costo, legitimando formas de trabajo al margen de cualquier regulación y remuneración debida"33.

Ainda para Felipe,

Las consecuencias del trabajo de Profesoras y Profesores a Honorarios en la Universidad, aunque si bien no es ad honorem, tiene como consecuencia la legitimación de un tipo de trabajo precario, que deposita en las espaldas de miles de Profesoras y Profesoras el sostenimiento de un Sistema Universitario orientado al mercado y la competencia ${ }^{34}$.

Antonio Julio enfatizou que as consequências podem ser sérias. "Cito como exemplo um concurso para professores de História que seria realizado na Universidade Federal de Minas Gerais (UFMG) na modalidade contrato voluntário. A proposta recebeu reações contrárias e o concurso acabou cancelado. Considero importante analisar as consequências sérias que poderia ter para uma universidade do porte da UFMG. Também tomei conhecimento de outros concursos para professores voluntários sendo realizados em universidades públicas no Brasil". Para o professor, "existe toda uma tentativa por parte dos

32 “ser docente universitário proporciona prestígio e formação que são positivamente valorizados no currículo vitae. O fato de aceitar trabalhar como ad-honorem pode ser uma oportunidade para entrar no âmbito acadêmico. Segundo Adriana, "Quem ganham são as autoridades, que economizam em orçamento. E o próprio capital, que disputa pelo destino que lhes dão aos fundos públicos. Quem perde são os trabalhadores, tanto os que trabalham sem ser remunerados como os que recebem sua remuneração, já que repercute na "flexibilização" das condições de trabalho de todo o coletivo de docentes."

33 "as consequências de trabalho de Professores Assistentes ad honorem na Universidade têm como consequência o acesso ao apoio de estudantes ou profissionais às atividades de Docência sem custo, legitimando formas de trabalho à margem de qualquer devida regulamentação e remuneração."

34 “As consequências de trabalho de Professoras e Professores a Honorários na Universidade, ainda que, embora não sejam ad honorem, têm como consequência a legitimação de um tipo de trabalho precário, que deposita nas costas de milhares de Professoras e Professores a sustentação de um Sistema Universitário orientado ao mercado e à competência."

RPGE- Revista on line de Política e Gestão Educacional, Araraquara, v. 24, n. esp. 1, p. 909-937, ago. 2020. e-ISSN:1519-9029. DOI: https://doi.org/10.22633/rpge.v24iesp1.13787 
governos de precarizar o trabalho docente universitário. Por isso é muito importante que este voluntariado nas universidades seja substituído por outra forma de contratação com funções definidas claramente". Adriana, por sua vez, lembrou que

en Argentina, es un tipo de trabajo que ha permitido acompañar al proceso de expansión del ingreso y de la matrícula de la universidad pública, pero a costa del recorte de los derechos de los trabajadores. La universidad es pública, gratuita y de ingreso irrestricto, pero esta situación no ha sido acompañada por una adecuada inversión presupuestaria”. Segundo Adriana, "basta con revisar los datos de la Universidad de Buenos Aires (UBA) para comprobar que una importante porción del servicio educativo es sostenida, a costa del trabajo voluntario". Adriana ainda acrescentou que "al mismo tiempo, es un tipo de trabajo que ha sido funcional a las lógicas de nombramiento discrecional y al estancamiento del funcionamiento de los sistemas de concursos públicos. Todos estos aspectos pueden ser pensados como factores que pueden repercutir en el deterioro de la calidad académica ${ }^{35}$.

$\mathrm{Na}$ sequência, perguntou-se aos professores sobre as implicações do trabalho voluntário sobre o trabalho dos docentes efetivos (P8). Felipe afirmou que

no hay trabajo voluntario o ad honorem que compita con el trabajo de las y los docentes efectivos. La figura del trabajo a honorarios, que insisto no es ad honorem, potencialmente sí genera el desarrollo de actitudes de protección al puesto de trabajo de las y los docentes efectivos. No son visibles pautas de organización y acción de las y los docentes efectivos a nivel nacional para acabar con el Trabajo Docente a Honorarios ${ }^{36}$.

Para Antonio Julio,

trata-se de um problema político que deverá ser enfrentado com seriedade. Essa modalidade de trabalho docente poderá ser implantada para precarizar e substituir docentes, inclusive na graduação. Mas também pode ser positivo se houver um outro enquadramento que não seja como 'voluntário' e que tenha normas bem definidas para que o professor aposentado não seja apenas 'substituto' de novos professores.

35 "na Argentina, é um tipo de trabalho que permitiu acompanhar o processo de expansão do ingresso e da matrícula na universidade pública, mas a custo do corte dos direitos dos trabalhadores. A universidade é pública, gratuita e de ingresso irrestrito, mas esta situação não foi acompanhada por um adequado investimento orçamentário". Segundo Adriana, "basta revistar os dados da Universidade de Buenos Aires (UBA) para comprovar que uma importante porção de serviço educacional é sustentada, a custo do trabalho voluntário". Adriana ainda acrescentou que "ao mesmo tempo, é um tipo de trabalho que foi funcional às lógicas de nomeação discricional e ao estancamento do funcionamento dos sistemas de concursos públicos. Todos estes aspectos podem ser pensados como fatores que podem repercutir no deterioramento da qualidade acadêmica."

${ }^{36}$ não há trabalho voluntário ou pro bono que concorra com o trabalho de professores reais. A figura do trabalho honorário, que insisto não é ad honorem, potencialmente gera o desenvolvimento de atitudes de proteção ao trabalho de professores efetivos. Não há diretrizes visíveis para a organização e ação de professores efetivos em nível nacional a fim de pôr um fim ao trabalho honorário. 
Também Adriana entende que "la existencia de este tipo de trabajo puede ser un factor que incida en la complejización de la disputa por la mejora de las condiciones laborales, en términos de salario, herramientas de trabajo, derechos generales y también en cuanto a la transparencia del sistema de acceso a los cargos o de promoción". 37

Considerou-se importante saber se a presença do professor voluntário traz alguma implicação sobre os quantitativos de docentes efetivos na universidade (P9). Segundo Felipe, para maior entendimento, essa questão demanda investigação interna nas instituições.

Para Antonio Julio, trata-se de um

problema político sério que deverá ser enfrentado com seriedade. Por um lado, poderá ser implantado para precarizar e substituir docentes, inclusive na graduação. Por outro lado, poderá ser positivo se for implementado em outro formato que não seja como 'voluntário' e que tenha normas bem definidas para que o professor voluntário não seja 'substituto' de novos professores.

Adriana, também afirmou que "na medida en que se contratan docentes sin retribución, la universidad adquiere la posibilidad de desempeñar sus funciones a expensas del estancamiento de la planta de docentes remunerados". Para Adriana "esto lesiona profundamente la situación general de los trabajadores docentes"38.

Perguntados sobre os pontos positivos e negativos do trabalho docente universitário voluntário (P10), Felipe destacou que "en el caso de los ayudantes de Cátedra ad honorem, tienen como punto positivo el acceso abierto a formas de valorización de la trayectoria académica en un nivel inicial, abierto para todas y todos en relación de sus resultados académicos" ${ }^{\prime 39}$.

Ainda de acordo com Felipe, "el punto negativo tiene que ver con la idea de trabajar a cambio de ninguna retribución económica, aunque sea en un nivel bajo. En un contexto profundamente mercantilizado como el chileno, no corresponde que existan espacios de trabajo no remunerado en contextos de alto movimiento y generación de lucros"40.

37 “a existência deste tipo de trabalho pode ser um fato que incida na complexidade da disputa pela melhora das condições trabalhistas, em termos de salário, ferramentas de trabalho, direitos gerais e também quanto à transparência do sistema de acesso aos cargos ou de promoção."

38 "na medida em que os professores são contratados sem remuneração, a universidade adquire a possibilidade de desempenhar suas funções às custas da estagnação do corpo docente remunerado". Para Adriana "isso prejudica profundamente a situação geral dos trabalhadores docentes."

39 "no caso dos Professores Assistentes ad honorem, têm como ponto positivo o acesso aberto aos modos de valorização da trajetória acadêmica em um nível inicial, aberto para todas e todos com relação a seus resultados acadêmicos."

40 “o ponto negativo se relaciona à ideia de trabalhar em troca de nenhuma retribuição econômica, ainda que seja em um baixo nível. Em um contexto profundamente mercantilizado como o chileno, não significa que existam espaços de trabalho não remunerado em contexto de alto movimento e geração de lucros.”

RPGE- Revista on line de Política e Gestão Educacional, Araraquara, v. 24, n. esp. 1, p. 909-937, ago. 2020. e-ISSN:1519-9029. DOI: https://doi.org/10.22633/rpge.v24iesp1.13787 
Antonio Julio considerou que "o voluntariado não deveria existir no serviço público. Seria importante garantir outra forma de contrato, remunerado, de modo que o docente aposentado pudesse contribuir com atividades específicas e delimitadas". Sobre o aspecto negativo, Antonio Julio citou “o próprio conceito de 'voluntário' no serviço público, denota certa inferioridade". Adriana, por sua vez, afirmou que:

no veo puntos positivos desde el punto de vista de los intereses del colectivo de trabajadores. Desde el punto de vista individual de quien decide trabajar en forma voluntaria, puede ser positivo el hecho de que esto represente una posibilidad de acceso al campo laboral, a tener un mejor currículum vitae, o del acceso a diversas actividades propias del 'mundo académico'. Puede ser también una experiencia de formación personal. En situaciones excepcionales, como en el caso de los docentes extranjeros, el formato 'trabajo voluntario' puede resultar una oportunidad para el desarrollo de ciertos proyectos institucionales de interés. De todos modos, considero que podría revisarse esta categorización que, por lo que se puede apreciar, abarca a una diversidad de situaciones ${ }^{41}$.

Quanto aos pontos negativos, para Adriana seriam, entre outros: "deterioro de las condiciones laborales en diversos aspectos; desigualdad en el acceso a los cargos, desvalorización del salario; aumento de las cargas laborales e deterioro de la calidad de la enseñanza" ${ }^{\prime 42}$.

$\mathrm{Na}$ penúltima questão, considerou-se relevante saber aspectos da avaliação do sindicato local e do sindicato nacional dos docentes universitários sobre o trabalho docente voluntário na universidade, conhecer ações do sindicato e uma avaliação do sindicato sobre essa modalidade de trabalho docente (P11). De acordo com Felipe,

no existe Sindicato Nacional de Docentes Universitarios no Chile. En los Sindicatos Docentes de cada Universidad podrían levantarse pautas de acción. En el Sindicato de la Universidad en que trabajo sólo se ha avanzado en incluir a las y los Profesores a Honorarios al acceso de algunos de los puntos de la negociación colectiva. Por ejemplo, las y los Profesores Efectivos y a Honorarios tienen descuentos en el pago de arancel mensual si potencialmente sus hijas o hijas estudian en la Universidad. Creo que a nivel de cada Universidad y a nivel nacional es necesaria una articulación de las y los Docentes, tanto Efectivos como a Honorarios, para influir en las condiciones en que su trabajo se realiza". Antonio Julio

41 “não vejo pontos positivos do ponto de vista dos interesses coletivos dos trabalhadores. Do ponto de vista individual de quem decide trabalhar de forma voluntária, pode ser positivo o fato de que isso represente uma possibilidade de acesso ao campo de trabalho, a ter um melhor currículo vitae, ou do acesso a diversas atividades próprias do 'mundo acadêmico'. Pode ser também uma experiência de formação pessoal. Em situações excepcionais, como no caso dos docentes estrangeiros, o formato 'trabalho voluntário' pode resultar uma oportunidade para o desenvolvimento de certos projetos institucionais de interesse. De qualquer forma, considero que se poderia revisar esta categorização que, pelo que se pode perceber, engloba diversas situações."

42 "deterioração das condições de trabalho em vários aspectos; desigualdade no acesso a vagas, desvalorização dos salários; aumento da carga de trabalho e deterioração da qualidade do ensino." 
afirmou que "apesar de um pouco afastado das ações sindicais, avalia que as ações são mínimas ou nenhuma. Trata-se de uma pauta muito importante para os docentes que estão atuando como voluntários, para a categoria e para a universidade como um todo",43.

Adriana, por sua vez, destacou que

las federaciones sindicales nacionales (Federación Nacional de Docentes Universitarios (CONADU), Federación Nacional de Docentes, Investigadores y Docentes Universitarios (CONADUH), Federación de Docentes de las Universidades (FEDUN) como la gremial docente de la Universidad Nacional de Luján (UNLu) denominada Asociación de Docentes de la Universidad Nacional de Luján (ADUNLu) comparten una mirada crítica del trabajo ad-honorem. Lo analizan como una forma de empleo que favorece el estancamiento del presupuesto destinado a la educación, la desigualdad en la distribución de los fondos entre universidades (y facultades) y en el acceso a los cargos. Se reconoce que el crecimiento de esta modalidad ha 'acompañado' la expansión del ingreso a la universidad pública y la masividad",4.

Adriana acrescentou que, deste modo,

entiendo que se captura la perversidad de un mecanismo por el cual el sistema no asume la responsabilidad de destinar los fondos suficientes como para garantizar una democratización real del acceso a la educación. Sé fehacientemente que, desde CONADUH, desde hace por lo menos quince años que se ha tomado la situación de los docentes ad-honorem como una problemática de la agenda sindical. A su vez, las negociaciones paritarias han incluido la discusión de acciones destinadas a regularizar la situación de los docentes ad-honorem" $"$.

Nesse sentido, para Adriana, "se pueden ver algunos detalles de las acciones realizadas. Por ejemplo, relevamiento de los docentes que se encuentran en esta situación,

43 “não há Sindicato Nacional de Docentes Universitários no Chile. Nos Sindicatos de cada Universidade poderiam ser levantadas pautas de ação. No Sindicato da Universidade em que trabalho apenas se tem avançado em incluir as e os Professores Honorários ao acesso de alguns dos pontos de negociação coletiva. Por exemplo, as e os Professores Efetivos e a Honorários têm descontos no pagamento de mensalidades, no caso de ter filhos ou filhas que estudam na Universidade. Acredito que a nível de cada Universidade é necessária uma articulação das e dos Docentes, tanto Efetivos como Honorários, para influenciar nas condições em que seu trabalho se realiza."

44 “as federações sindicais nacionais (Federação Nacional de Docentes Universitários (CONADU), Federação Nacional de Docentes, Pesquisadores e Docentes Universitários (CONADUH), Federação de Docentes das Universidades (FEDUN) como o sindicato docente da Universidade Nacional de Luján (UNLu) denominada Associação de Docentes da Universidade Nacional de Luján (ADUNLu) compartilham um olhar crítico do trabalho ad-honorem. O analisam como uma forma de emprego que favorece ao estancamento do orçamento destinado à educação, à desigualdade na distribuição dos fundos entre universidades (e faculdades) e no acesso aos cargos. Reconhece-se que o crescimento dessa modalidade "acompanhou" a ampliação da entrada na universidade pública e a massificação."

45 “entendo que a perversidade de um mecanismo é capturada pela qual o sistema não assume a responsabilidade de alocar fundos suficientes para garantir uma democratização real do acesso à educação. Sei com certeza que, desde CONADUH, desde há pelo menos quinze anos que se tem tomado a situação dos docentes ad-honorem como uma problemática da agenda sindical. Por sua vez, as negociações paritárias tem incluído a discussão de ações destinadas a regulamentar a situação dos docentes ad-honorem.”

RPGE- Revista on line de Política e Gestão Educacional, Araraquara, v. 24, n. esp. 1, p. 909-937, ago. 2020. e-ISSN:1519-9029. DOI: https://doi.org/10.22633/rpge.v24iesp1.13787 
conformación de comisiones. Asimismo, todo el trabajo realizado en el proceso de negociación del convenio colectivo de trabajo puede ser considerado un avance al respecto"46.

Finalmente, considerou-se importante saber se os entrevistados pretendiam assumir trabalho voluntário quando se aposentassem e os motivos dessa escolha (P12). Felipe argumentou que

\begin{abstract}
en el caso que llegase a existir Trabajo Docente Universitario ad honorem en el Sistema Universitario chileno no lo realizaría debido a que no es una figura laboral que me agrade. Sí lo haría en el caso de la existencia de un tipo de Sistema Universitario Público, Laico y Gratuito volcado al atendimiento de la sociedad chilena y sus necesidades más urgentes, a modo de un proyecto político y cultural más amplio". Tendo em vista o cenário atual, Antonio Julio afirmou que "meu projeto é permanecer na instituição até fevereiro de 2022, quando meus orientandos deverão ter concluído o curso". Também Adriana revelou que "en primera instancia, plantearía que no. De acuerdo con la ley que regula mi situación previsional, recién estaría en condiciones de jubilarme dentro de diez años. Es muy difícil aventurar una respuesta definitiva y excluir la posibilidad de que llegare a presentarse alguna posibilidad de dar continuidad a alguna tarea académica que, en ese momento, pudiere resultarme de interés y que la opción para llevarla a cabo sea la de trabajar bajo la modalidad ad-honorem ",47.
\end{abstract}

\title{
Considerações finais
}

Ao concluir esse artigo, torna-se relevante retomar os objetivos que o motivaram, a saber: captar o contexto em que o trabalho voluntário em geral e docente surgiu na Argentina, Brasil e Chile por meio dos depoimentos de docentes entrevistados e, além disso, verificar normatizações nacionais acerca do trabalho docente voluntário e institucionais, das universidades em cada país, como também verificar como ele se concretiza na prática docente e como é percebido pelos entrevistados.

A questão do trabalho docente voluntário em Instituições públicas de educação superior suscita muitas reflexões; trata-se de um tema polêmico que coloca em pauta tanto

\footnotetext{
46 "pode-se ver alguns detalhes das ações realizadas. Por exemplo, pesquisa com professores que estão nessa situação, formação de comissões. Também, todo o trabalho realizado no processo de negociação do convênio coletivo de trabalho pode ser considerado um avanço em relação a isso."

47 "na hipótese de que chegasse a existir um Trabalho Docente Universitário ad honorem no Sistema Universitário chileno não o realizaria devido a que não é uma figura laboral que me agrade. Se o fizesse, seria no caso da existência de um tipo de Sistema Universitário Público, Laico e Gratuito voltado ao atendimento da sociedade chilena e suas necessidades mais urgentes, ao modo de um projeto político atual mais amplo". Tendo em vista o cenário atual, Antonio Julio afirmou que "meu projeto é permanecer na instituição até fevereiro de 2022, quando meus orientandos deverão ter concluído o curso". Também Adriana revelou que "em primeiro lugar, eu argumentaria que não. De acordo com a lei que regulamenta minha situação previdenciária, eu só poderia me aposentar em dez anos. É muito difícil arriscar uma resposta definitiva e excluir a possibilidade de que possa encontrar alguma oportunidade de dar continuidade a uma tarefa acadêmica que, neste momento, poderia ser de meu interesse e que a condição para realizá-la seja trabalhar sob a modalidade ad honorem.”
} 
questões políticas como princípios pessoais e coletivos sobre o trabalho, categoria central na existência humana, especificamente no caso do trabalho docente numa instituição pública.

Os depoimentos dos docentes entrevistados indicam a ocorrência, há tempos, desse tipo de trabalho nas universidades nos países, e que este vem ganhando mais vigor desde a década de 1990, sendo reconhecido, de um lado, como forma de aquisição de experiência e acesso à carreira acadêmica e, por outro, como mecanismo de precarização do trabalho docente, pela ausência de remuneração, a baixa remuneração de algumas categorias quando há, a negação de garantias trabalhistas que correspondem ao trabalho formal, a flexibilização das condições de trabalho do conjunto da categoria, pela funcionalidade às iniciativas de nomeação discricionária, o estancamento de vagas e de concursos públicos, a economia de orçamento do Estado no setor a custa da perda de qualidade do ensino, que é agravada com sucessivas reformas curriculares de caráter mercantil.

Torna-se relevante também destacar o agravamento da divisão da categoria, o que dificulta ainda mais a organização coletiva dos docentes universitários em torno de seus interesses comuns e aos da classe trabalhadora.

Embora a superação desse tipo de trabalho já tenha se constituído ponto de pauta de reivindicação de alguns sindicatos docentes, como na Argentina, no Chile, que não possui sindicato nacional, e no Brasil, esse tipo de pauta ainda precisa ser valorizado na agenda sindical.

Nota-se que, ainda que sob diferentes denominações, o trabalho docente voluntário tem servido para sustentar políticas de exploração do trabalho docente por parte do Estado/Empresas, e que as anunciadas tentativas para a sua suposta extinção, na realidade acabam criando novas e reiteradas formas para dar continuidade a essa exploração, seja pela baixa remuneração de docentes, como os docentes s, no Chile, seja pela ausência de retribuição salarial, ou ainda por extensão do voluntariado aos estudantes. O caso dos convênios coletivos na Argentina, e do ajudante de cátedra, no Chile, são notórios nesse sentido. No Brasil, verificou-se iniciativas implantas nesta direção, a exemplo do Programa de Residência Pedagógica, instituído por Decreto em 2016 e regulamentado em 2018. Tal programa incentiva as instituições de educação superior públicas e privadas e as escolascampo do país a utilizarem estudantes/bolsista-residentes, a substituírem professores nos seus impedimentos, mascarando a falta numérica de docentes nas escolas, concorrendo assim, para ampliar a precarização do trabalho docente, a desvalorização dos professores da educação básica e a formação inicial dos professores, que passa a enfatizar a prática, em detrimento do desenvolvimento do pensamento crítico.

RPGE- Revista on line de Política e Gestão Educacional, Araraquara, v. 24, n. esp. 1, p. 909-937, ago. 2020. e-ISSN:1519-9029. DOI: https://doi.org/10.22633/rpge.v24iesp1.13787 
Os entrevistados demonstraram ter consciência de que o trabalho voluntário contribui para a precarização e o desgaste do trabalho docente em seu país. Talvez por esse motivo, tanto Felipe quanto Adriana afirmaram não pretender se tornar voluntários quando se aposentarem. Já Antonio Julio, recém aposentado e ingresso na condição de voluntário, afirma estender essa posição até 2022, em função das orientações de Pós-graduação que realiza. E é justamente ele que em vários momentos da sua entrevista renega o trabalho voluntário e reivindica sua extinção/substituição por trabalho remunerado.

Pode-se inferir que a despeito dos aspectos negativos do voluntariado docente na universidade, incluindo os interesses dos governantes e empresários, e ainda os prováveis oportunismos de alguns docentes, há elementos que indicam contradições nesse processo. A permanência do vínculo com estudantes, com grupos de pesquisa, ou grupos políticos de caráter crítico, pode representar uma estratégia individual de resistência ativa, no sentido atribuído por Bernardo (1991). Convém lembrar que esse tipo de resistência por ser individual está condenado de antemão a não ultrapassar o âmbito do capitalismo e a não contestar o seu principal fundamento. Ainda que ativa, pois cada trabalhador arrisca o conflito aberto ainda que dissimulado, não deriva de decisão em conjunto, e não possui complementaridade tática entre as suas ações. De toda forma, é na experiência de luta que a consciência dos trabalhadores pode avançar, para transformar a multiplicidade de lutas, em luta coletiva e ativa, a única capaz de subverter a ordem capitalista.

Finalmente, por esse entendimento da positividade da luta dos trabalhadores, considera-se relevante destacar que as pesquisas sobre esse tema apresentadas nesse artigo também podem ser consideradas como ações de resistência. $\mathrm{Na}$ medida em que se problematiza esse contexto nos meios acadêmicos, pode se alertar para a necessidade de superar o atual modelo de trabalho docente voluntário, o modelo de trabalho precário na sociedade contemporânea e a própria sociedade na forma em que ela se funda. Por essa razão, agradecemos aos colegas entrevistados, Adriana, Antônio Júlio e Felipe, por socializarem seus conhecimentos, perspectivas e posicionamentos essenciais na organização deste artigo.

Concluindo, espera-se que as discussões geradas nesse artigo estimulem o aprofundamento das discussões a respeito dos motivos que levam à permanência no trabalho voluntário nas universidades, suas consequências e alternativas. Sugere-se o desenvolvimento de outras possibilidades de estudos sobre o tema com docentes voluntários de outras universidades federais, abrangendo várias regiões no país, e também estudos comparados com docentes de outras áreas de atuação. Ainda, na perspectiva da internacionalização, a ampliação do estudo para outros países da América Latina e outras regiões. 


\section{REFERÊNCIAS}

BERNARDO, J. Economia dos conflitos sociais. São Paulo: Cortez, 1991.

BOSI, A. P. A precarização do trabalho docente nas instituições de ensino superior no Brasil nesses últimos 25 anos. Educ. Soc., Campinas, v. 28, n. 101, p. 1503-1523, set./dez. 2007. Disponível em https://www.scielo.br/pdf/es/v28n101/a1228101.pdf. Acesso em: 05 abr. 2020.

CABRALES SALAZAR, O. Los nuevos modelos de gestión en las universidades y en el trabajo docente en Colombia. RPGE - Revista on line de Política e Gestão Educacional, Araraquara, v. 22, n. esp.1, p. 193-208, mar., 2018. Disponível em:

https://periodicos.fclar.unesp.br/rpge/article/view/10790/7198. Acesso em: 10 fev. 2020.

CANTILLANA-BARAÑADOS, R.; PORTILLA-VÁSQUEZ, I. Por la senda de los 'profesores taxis': los efectos de la desprofesionalización académica en educación superior. Una aproximación cualitativa desde Chile. Cultura-hombre-sociedad, v. 29, n. 1, p. 306-330, 2019.

FERRO, O. M. dos R.; SILVA, I. A. da. O trabalho docente no ensino superior: da base técnica manufatureira contida na didática comeniana à flexibilização, simplificação e precarização do trabalho na contemporaneidade. RPGE - Revista on line de Política e Gestão Educacional, [S.1.], n. 13, fev. 2017. Disponível em: https://periodicos.fclar.unesp.br/rpge/article/view/9335/6187. Acesso em: 05 abr. 2020.

GUIMARAES, V. N.; SOARES, S. V.; CASAGRANDE, M. D. H. Trabalho docente voluntário em uma Universidade Federal: nova modalidade de trabalho precarizado? Educ. rev., Belo Horizonte, v. 28, n. 3, p. 77-101, set. 2012. Disponível em:

http://www.scielo.br/scielo.php?script=sci_arttext\&pid=S0102-

$46982012000300004 \& \operatorname{lng}=$ en\&nrm=iso. Acesso em: 02 out. 2019.

KRAWULSKIL, E.; BOEHSLL, S. T. M; CRUZLLL, K. O.; MEDINA, P. F. Docência voluntária na aposentadoria: transição entre o trabalho e o não trabalho. Psicol. teor. prat., São Paulo, v. 19, n. 1, p. 55-66, abr. 2017. Disponível em: http://pepsic.bvsalud.org/scielo.php?script=sci_arttext\&pid=S151636872017000100004\&lng=pt\&nrm=iso. Acesso em: 29 mai. 2019.

KRAWULSKI, E., RIBEIRO, A. C. A. Aposentadoria, docência e trabalho voluntário: tecendo aproximações. In: QUIROGA, V. F.; CATTANEO, M. R. (Orgs.). Transformaciones en las organizaciones del trabajo: salud y ampliación de ciudadanía. 1. ed. Rosario, Argentina: Editora da Universidad Nacional de Rosario, 2013. p. 239-245.

MOREIRA, F. A.; SILVA, M. V. Trabalho docente na esfera pública: controvérsias e vicissitudes sob a ótica dos sujeitos da educação. RPGE - Revista on line de Política e Gestão Educacional, [S.1.], n. 10, jan. 2017. Disponível em: https://periodicos.fclar.unesp.br/rpge/article/view/9300/6164. Acesso em: 02 jan. 2020.

RIVIERA, F. Construir la patria nueva. Los trabajos voluntarios en la Universidad Técnica del Estado (Chile, 1964-1973). Revista La Cañada: pensamiento filosófico chileno, n. 3, p. 201-225, 2012.

RHODEN, J.L.M.; BOLZAN, D.P.V. "LONGEDOCÊNCIA” NO ENSINO SUPERIOR: o (re) investimento de professores voluntários após a aposentadoria. Cad. Pesq., v. 26, n. 3, p. 164-186, jul. /set. 2019. Disponível em:

http://www.periodicoseletronicos.ufma.br/index.php/cadernosdepesquisa/article/view/12757/6906.

Acesso em: 12 jan. 2020.

RPGE- Revista on line de Política e Gestão Educacional, Araraquara, v. 24, n. esp. 1, p. 909-937, ago. 2020. e-ISSN:1519-9029. DOI: https://doi.org/10.22633/rpge.v24iesp1.13787 
RIBEIRO, L. J. B.; SMEHA, L. N. O que me leva a continuar? A permanência do professor universitário aposentado no exercício de sua profissão. Disciplinar um Scientia Série Ciências Humanas, v. 10, n. 1, p. 179-194, 2009.

Disponível em: http://sites.unifra.br/Portals/36/Artigos\%202009\%20CH/13.pdf. Acesso em: 18 set. 2019.

SGUISSARDI, V.; SILVA JÚNIOR, J. R. Trabalho intensificado nas federais: pós-graduação e produtivismo acadêmico. São Paulo: Xamã, 2009.

SILVA JÚNIOR, J. dos R. The New Brazilian University - A busca por resultados comercializáveis: para quem? Marília: Projeto Editorial Práxis, Rede de Estudos sobre o Trabalho, 2017.

\section{Como referenciar este artigo}

MELO, S. D. G.; GOMES, S. dos S. Trabalho docente voluntário na Educação Superior: precarização das condições de trabalho na Argentina, Brasil e Chile. Revista on line de Política e Gestão Educacional, Araraquara, v. 24, n. esp. 1, p. 909-937, ago. 2020. eISSN:1519-9029. DOI: https://doi.org/10.22633/rpge.v24iesp1.13787

Submetido em: 20/02/2020

Revisões requeridas: $30 / 04 / 2020$

Aprovado em: 28/06/2020

Publicado em: 01/08/2020 